\title{
Capacity to consent to sexual relationships in adults with learning disabilities
}

\author{
Glynis H Murphy, PhD, FBPsS, Professor of Clinical Psychology of Learning Disabilities, Tizard Centre, University of Kent, \\ Canterbury, UK
}

Correspondence: Prof. G Murphy, Tizard Centre, University of Kent, Canterbury, Kent CT2 7LZ, UK.

Tel: +44 (0) 1227 827989. E-mail: g.h.murphy@kent.ac.uk

(Accepted 18th May 2003)

Journal of Family Planning and Reproductive Health Care 2003; 29(3): 148-149

\begin{abstract}
People with learning disabilities used to be seen as asexual or promiscuous and were discouraged from expressing their sexuality. However, with the growth of the rights movement, attention has turned to the dilemma of how to both empower and protect people with learning disabilities in relation to their sexuality. A recent research project showed that, on average, adults with learning disabilities knew much less about sex and understood much less about sexual abuse than non-disabled young people aged 16 years. Sex education made a significant difference to their knowledge and understanding however. The implications of the study for services for people with learning disabilities and for definitions of capacity to consent to sexual relationships are discussed.
\end{abstract}

\section{Key message points}

- People with learning disabilities used to be seen as either 'asexual' or as dangerously promiscuous, leading to institutionalisation (e.g. in the UK) and/or compulsory sterilisation (e.g. in the USA).

- Expression of sexuality is now viewed as a rights issue and is considered part of an 'ordinary life'.

- Some special protection exists in law for people with severe learning disabilities in the $\mathrm{UK}$, in that they are currently deemed unable to consent to sexual relationships.

- Research shows that adults with mild learning disabilities know much less about sex and also understand less about sexual abuse than non-disabled 16-year-olds.

- Sex education makes a significant difference to the sexual knowledge and understanding of abuse of adults with learning disabilities and should be widely available on demand.

- The new sexual offences law in the UK will include updated definitions of capacity to consent to sexual relationships, which are relevant to people with learning disabilities.

\section{Background}

During the early twentieth century, there were two contradictory beliefs about people with learning disabilities and sexuality, ${ }^{1}$ namely that (1) they were essentially asexual 'eternal children' 2 and (2) they were a threat to society because they would reproduce excessively and thereby threaten the national heritage of intelligence. ${ }^{3}$ Such attitudes led to the segregation of people with learning disabilities in institutions (e.g. in the UK) and to compulsory sterilisation laws in some countries (e.g. in the USA, Scandinavia).

Attitudes began to change, however, with the advent of the normalisation and rights movements, ${ }^{4,5}$ which led to a growing empowerment of people with learning disabilities and a widening acceptance of their rights in relation to recognition of their sexual needs. As a result, sex education packages began to be designed and delivered. $2,6,7$

However, just as this rights perspective began to gain ground, evidence emerged of high rates of sexual abuse amongst people with learning disabilities. ${ }^{8-10}$ It seemed, therefore, that there was a need to both empower people with learning disabilities to make their own sexual choices and to protect them from abuse.

\section{The law}

In some countries, including England and Wales, there is some protection in law against unwanted sexual advances for people with learning disabilities. ${ }^{11}$ Briefly, people with severe learning disabilities [broadly speaking, this refers to people with an intelligence quotient (IQ) below 50] have special protection in law and are deemed unable to consent, so that sexual relationships with a man or woman with severe learning disabilities constitutes an offence (under the Sexual Offences Acts 1956 and 1967). There is also special protection afforded to people with learning disabilities under the Mental Health Act, such that sexual relationships between staff and service users are also an offence. In both cases, however, maximum sentences are brief ( 2 years). Otherwise, people with learning disabilities are deemed in law to be able to consent to sexual relationships and they have the same protection against sexual abuse as other members of society.

\section{Capacity to consent}

The decision-making capacity of vulnerable people, including those with learning disabilities, has been much debated in recent years, with considerable amounts of research $^{12,13}$ and policy emerging. ${ }^{14-17}$ In the UK and elsewhere, the functional approach has been preferred to the diagnostic and outcome approaches to capacity ${ }^{18}$ and the Law Commission ${ }^{15}$ has suggested that people should be: 'enabled and encouraged to take for themselves those decisions that they are able to take'.

Much research and policy on decision-making capacity has concerned consent to treatment. There has been far less consideration of capacity to consent to sexual relationships. Nevertheless, according to the British Medical Association (BMA) and Law Society guide ${ }^{14}$, in order to be considered able to consent to sexual activity, an individual: '(a) must be capable of understanding what is proposed and its implications; and (b) must be able to exercise choice. (It is important to consider whether one party is in a position of power which will influence the ability of the other party to consent.)' (p. 59).

This definition of capacity has not always been accepted in court, however. ${ }^{19}$ In the case of R v. Jenkins, for example, a woman with severe learning difficulties was made pregnant by a support worker. The young woman had no understanding about her pregnancy. The support worker admitted having sex with the woman and the Crown Prosecution Service (CPS) had two potential alternatives: to charge him under Section 7 of the Sexual Offences Act with having 'sex with a mental defective' or to charge him with rape. They decide to charge him with rape, because a conviction under Section 7 only carried a 2-year sentence. It thus had to be proved whether or 
not the victim had the capacity to consent to sexual intercourse (and whether or not she had consented). An assessment by the expert witness for the prosecution showed that the young woman did not have the capacity to consent to sexual relationships, as defined by the BMA and Law Society guidance, ${ }^{19}$ since she could not identify many basic body parts and could not tell the difference between pictures of sexual intercourse and other pictures.

However, the expert witness for the defence argued that the woman had capacity to consent to sexual relationships because she seemed to like the alleged perpetrator (and did not avoid him, for example). An argument was put forward by the judge that the BMA and Law Society guidance was wrong. He held that it "was not necessary to understand the implications of sexual intercourse, only to have an understanding of the act itself and that there was therefore no case to answer'. ${ }^{19}$ The alleged perpetrator thus walked free. This case highlighted the extreme vulnerability of adults with severe learning difficulties and showed how the criminal justice system can fail to protect them.

\section{The research project}

We felt that there needed to be better evidence gathered about the capacity of people with learning disabilities to consent to sexual relationships. We therefore conducted a research project in which we assessed the sexual knowledge, social networks and understanding of abuse of 60 adults with learning disabilities and 60 young people without disabilities. ${ }^{20}$ The young people selected were 16year-olds from the general population, chosen because they are deemed to be able to consent to sexual relationships under English law. We found, on average, far lower levels of sexual knowledge and far higher levels of vulnerability (in terms of understanding abuse) amongst the people with learning disabilities than amongst non-disabled 16-17-yearolds.

Adults with learning disabilities often lacked important information and knowledge in a number of key areas, including pregnancy, contraception, sexually transmitted diseases, legal aspects of sex and sexual health (for example, $60 \%$ had not heard of AIDS and only $18 \%$ could identify condoms as a way of reducing the chance of HIV infection). Non-disabled young people had a far greater knowledge of all these areas. Adults with learning disabilities also showed limited understanding of consenting and non-consenting situations and often considered a consenting situation as 'wrong', while non-consenting situations were sometimes not recognised as abusive.

Some $(55 \%)$ of the adults with learning disabilities said they had had sex education, as compared to $98 \%$ of young people. Those people with learning disabilities, who had had sex education, did significantly better on sexual knowledge and vulnerability assessments.

\section{Implications}

The results of this study suggest that implementation of ongoing sex education is imperative for adults with learning disabilities, particularly with regard to sexual health and pregnancy, contraception, safe sex, abuse, and some aspects of the law (such as consent).

The study also raises the question of how to decide when a person 'knows enough' to be construed as having the capacity to consent to sexual relationships. A number of ways of setting a minimum criterion for capacity to consent to sexual relationships were considered. The best alternative seemed to be to set the criterion in terms of a social minimum of knowledge required to engage in sexual relationships. It was proposed that in order to be considered capable of consenting to sexual relationships, people should know:
- That sex is different from personal care.

- That penetrative vaginal sex can lead to pregnancy.

- That penetrative anal sex is associated with a risk of HIV/AIDS.

- That people have a choice about whether to engage in sexual relationships.

This suggestion was close to the BMA and Law Society guide's ${ }^{14}$ earlier proposal and was not unlike the proposal that the Home Office made (though it was perhaps more easily understood and more concrete): "A person should be regarded as unable to consent if $\mathrm{s} / \mathrm{he}$ is unable to understand the nature and reasonably foreseeable consequences of the act and the implications of the act and its reasonably foreseeable consequences'. 21

Even with a minimal definition of this kind, about $50 \%$ of the people with learning disabilities in the current research would have been deemed unable to consent (none of the young people would have been). It is important to note, though, that capacity to consent to sexual relationships, however it is defined, is not a static phenomenon. There was clear evidence that those people with learning disabilities who had had sex education were more knowledgeable and less vulnerable than others. Service users would certainly benefit from wider availability of sex education, in order to exercise their rights while at the same time protecting themselves from unwanted pregnancies and/or sexual abuse.

Statements on funding and competing interests

Funding. The author has received funding from the Nuffield Foundation. Competing interests. None identified.

References

1 McCarthy M. Sexuality and women with learning disabilities. London: Jessica Kingsley, 1999.

2 Craft A, Craft M. Sex education and counselling for mentally handicapped people. Tunbridge Wells: Costello, 1983.

3 Trent JW. Inventing the feeble mind: a history of mental retardation in the United States. Berkeley, CA: University of California Press, 1995.

4 Emerson E. What is normalisation? In: Brown H, Smith H (eds), Normalisation: a reader for the nineties. London: Routledge, 1992.

5 Rioux M. Disability: the place of judgement in a world of fact. J Intellect Disabil Res 1997; 4: 102-111.

6 Cambridge P. HIV, sex and learning disability. Brighton: Pavilion, 1997.

7 McCarthy M, Thompson D. Sex and the 3Rs. Brighton: Pavilion, 1998.

8 Sobsey D. Violence and abuse in the lives of people with disabilities: the end of silent acceptance? Baltimore, MD: Paul H Brookes: 1994.

9 Brown H, Stein J, Turk V. The sexual abuse of adults with learning disabilities; report of a second two-year incidence survey. Ment Handicap Res 1995; 8: 3-24.

10 McCarthy M, Thompson D. A prevalence study of sexual abuse of adults with learning disabilities referred for sex education. J Appl Res Intellect Disabil 1997; 10: 105-124.

11 Gunn MJ. Sex and the law: a brief guide for staff working with people with learning difficulties (4th edn). London: Family Planning Association, 1996.

12 Grisso T, Appelbaum PS. Assessing competence to consent to treatment: a guide for physicians and other health professionals. New York, NY: Oxford University Press: 1998.

13 Arscott K, Dagnan D, Stenfert Kroese B. Assessing the ability of people with a learning disability to give informed consent to treatment. Psychol Med 1999; 29: 1367-1375.

14 British Medical Association and Law Society. Assessment of mental capacity: guidance for doctors and lawyers. London: British Medical Association, 1995.

15 Law Commission. Mental incapacity, Report No. 231. London: Her Majesty's Stationery Office, 1995.

16 Lord Chancellor's Department. Who decides? Making decisions on behalf of mentally incapacitated adults. London: The Stationery Office, 1997.

17 Lord Chancellor's Department. Making decisions. London: The Stationery Office: 1999.

18 Murphy GH, Clare ICH. Adults' capacity to make legal decisions. In: Bull R, Carson D (eds), Handbook of psychology in legal contexts. Chichester: John Wiley \& Sons, 2003; 31-66.

19 Murphy G. Justice denied. Ment Health Care 2000, 3: 256-257.

20 O'Callaghan AC, Murphy GH. Capacity to consent to sexual relationships in adults with learning disabilities. Final Report to the Nuffield Foundation, 2002. Copies available from the author.

21 Home Office. Setting the boundaries: reforming the law on sex offences. London: Her Majesty's Stationery Office, 2000. 